EGU21-2952, updated on 10 Apr 2021

https://doi.org/10.5194/egusphere-egu21-2952

EGU General Assembly 2021

(c) Author(s) 2021. This work is distributed under

the Creative Commons Attribution 4.0 License.

\title{
Below the Mosul Dam Lake. Geomorphological reconstruction of historical fluvial pattern of the Tigris River
}

\author{
Luca Forti ${ }^{1,2}$, Andrea Pezzotta ${ }^{1}$, Eleonora Regattieri ${ }^{2}$, Guido Stefano Mariani ${ }^{3}$, Filippo Brandolini ${ }^{4}$, \\ and Andrea Zerboni ${ }^{1}$ \\ ${ }^{1}$ Dipartimento di Scienze della Terra "Ardito Desio", Università degli Studi di Milano, Milano, Italy (luca.forti@unimi.it) \\ ${ }^{2}$ Istituto di Geoscienze e Georisorse, Consiglio Nazionale delle Ricerche, Pisa, Italy \\ ${ }^{3}$ Dipartimento di Scienze Chimiche e Geologiche, Università degli Studi di Cagliari, Italy \\ ${ }^{4} \mathrm{McC}$ ord Centre for Landscape - School of History, Classics and ArchaeologyNewcastle University, Armstrong Building, \\ Newcastle upon Tyne - NE17RU (UK).
}

Located along the Tigris River in the Kurdistan Region of Iraq (KRI), the Mosul Dam reservoir is the second biggest dam of the Near East, and represents an important water storage for local human activities. The Dam was built between 1981 and 1988 north of the village of Eski Mosul; along this part of the Tigris River several archaeological sites were inundated. Analysis of historical images derived from Declassified Corona satellite acquired between December 1967 and August 1968 reveals seasonal changes of the Tigris riverbed, shifting across the hydrological year from meandering to anastomosing. The geomorphological mapping was carried out on the December 1967 and. in August 1968, Corona images were taken, in order to estimate the modification of several fluvial geomorphological elements such as floodplain and point, middle and longitudinal bars. Here, such evidence is compared with Landsat data collected between the 1990ies and today, in order to detect the first phases of filling of the basin and the control of inherited Tigris channel belt over the reservoir. Moreover, we also noticed an influence of the ancient Tigris course on is recent insertion into the lake. Our work permitted to reconstruct the ancient fluvial landscape below the Mosul Dam Lake, and its evolution in response to seasonal variation of the discharge. 